\title{
Tradisi Syaraful Anam dalam Kajian Living Hadis
}

\author{
Ilham Mustafa *) \\ Institut Agama Islam Negeri \\ Bukittinggi, Sumatera Barat, \\ Indonesia \\ E-mail: \\ ilhammustafa@iainbukittinggi.ac.id
}

\section{Ridwan}

STAI-PIQ, Sumatera Barat,

Indonesia

E-mail:

muhammadridwan2209@gmail.com

*) Corresponding Author

\begin{abstract}
Abstrak: Tulisan ini berupaya menyajikan fenomena tradisi Syaraful Anam bagi Masyarakat Malalo. Dimana aspek penting living hadis pada trasi Syaraful Anam yaitu aspek ibadah yang terus kokoh di masyarakat. Sehingga tradisi-tradisi seperti ini tetap ada di masyarakat. Penelitian ini adalah penelitian lapangan (Field Research): penelitian yang dilaksanakan dengan meneliti langsung ke lapangan yang sudah ditentukan sebagai objek penelitian. Dari hasil penelitian diketahui bahwa nilai-nilai living hadis dalam tradisi Syaraful Anam adalah pertama nilai religius yaitu pembacaan syaraful anam adalah bukti kecintaan masyarakat terhadap Rasulullah SAW. Kedua nilai sosial yaitu tradisi Syaraful Anam yang diadakan pada berbagai perayaan hari besar Maulid Nabi dan kegiatan lainnya memberikan tempat bagi masyarakat untuk bersosialisasi keagamaan. Ketiga nilai budaya yaitu syair dan lantunan shalawat dalam Syaraful Anam merupakan sebuah karya penghargaan kepada nabi Muhammad SAW, karena dekat dengan unsur-unsur sastra yang bermutu tinggi.
\end{abstract}

\begin{abstract}
This paper attempts to present the phenomenon of the Syaraful Anam tradition for the Malalo community. Where the important aspect of living hadith in the Syaraful Anam tradition is the aspect of worship that continues to be strong in society. So that traditions like this still exist in society. This research is a field research (Field Research): research carried out by examining directly to the field that has been determined as the object of research. From the results of the study, it is known that the values of living hadith in the Syaraful Anam tradition are the first religious values, namely the reading of the Nervoul Anam is proof of people's love for the Prophet Muhammad The two social values, namely the Syaraful Anam tradition which is held at various celebrations of the Prophet's Birthday and other activities provide a place for the community to socialize religiously. The three cultural values, namely poetry and chanting of shalawat in Syaraful Anam are a work of appreciation to the prophet Muhammad SAW, because they are close to high-quality literary elements.
\end{abstract}

Kata Kunci: Syaraful Anam, Duo Koto, Living Hadis.

\section{PENDAHULUAN}

Tradisi merupakan kebiasaan turun temurun yang tetap dilakukan oleh masyarakat, bisa menjadi kebiasaan, bisa juga disesuaikan dengan berbagai ritual adat dan keagaman. Tradisi biasanya dijalankan dengan turun temurun, bisa dengan informasi lisan atau tulisan. Hal ini bisa dilihat dari perilaku generasi sesudahnya.

Dalam kehidupan masyarak tidak bisa lepas dari tradisi dan kebudayaan. 
Menurut Emile Durhheim, "bahwa agama yaitu sumber semua dari kebudayaan yang paling tinggi nilainya, maka sepantasnya respon kebudayaan ini harus direalisasikan dan sangat dibutuhkan oleh masyarakat terutama terhadap nilai-nilai agama yang terkandung di dalamnya". (Thomas F. O'dea' 1996, 3)

Dalam Islam, al-Quran mempunyai kedudukan pertama sebagai acuan kehidupan, yang menjadi sumber dan aturan semua aspek hidup. Kemudian Rasulullah sabagai pembawa risalah untuk memberikan petunjuk kehidupan kepada umatnya. A'jaj Khatib menjelaskan bahwa hadis merupakan sumber syariat, dari hadis munculnya hukum syari'at dan adab di dalam Islam. (Endang Soetari' 2004, 28)

Bagi mayoritas umat Islam membaca shalawat telah menjadi suatu kebiasaan yang mendarah daging dan sebagai tradisi yang ada dalam kegiatan keagamaan umat. Tradisi ini berkembang karena faktor nabi sebagai tuntunan umat. Karena Nabi Muhammad adalah pemberi syafaat, sehingga bershalawat adalah bagian penting bagi umat Islam. (Muhammad Tarobin, tth) Di nusantra tradisi shalawat sudah menjadi pakaian bagi umat Islam seperti kegiatan lahiran, pesta pernikahan, slamatan, maulid, khataman al-Quran, khitan dan lain sebagainya.

Di Jorong Duo Koto Malalo, Kec. Batipuh Selatan Kab.Tanah Datar pada peringatan Maulid Nabi dilakukan pembacaan Syaraful Anam. Menurut Angku Imam ini merupakan bentuk aplikasi hadis nabi Muhammad SAW. Bershalawat ke atas nabi. Biasanya masyarakat melakukan pada bulan maulid dan berbagai perayaan lainnya.

Membaca Syaraful Anam juga dipercaya menghadirkan sosok nabi di dalam kehidupan. Sehingga dengan membacanya menambah keimanan dan kedekatan terhadap rasulullah. Untuk kitab Syaraful Anam sendiri di Jorong Duo Koto Malalo, angku lebih sering membaca yang bertulisan tangan langsung, meskipun versi cetak sudah ada.

Dengan demikian Penulis menulusuri hadis yang digunakan masyarakat sebagai motivasi dalam pelaksanaan tradisi tersebut. Kemudian penulis juga memfokuskan Peneliti memfokuskan pada konsep, tata cara pelaksanaan membaca Syaraful Anam 
yang terdapat pada masyarakat. Karena Untuk itu penulis memberi judul Tradisi Syaraful Anam di Jorong Duo Koto Nagari Guguak Malalo Kec.Batipuh Selatan Kab. Tanah Datar (Studi Living Hadis).

\section{METODE PENELITIAN}

Penelitian ini adalah penelitian lapangan (Field Research): penelitian yang dilaksanakan dengan meneliti langsung ke lapangan yang sudah ditentukan sebagai objek penelitian. Sementara metode penilitian yang digunakan yaitu metode penulisan deskriptif analitis.

Penelitian ini dilakukan di Jorong Duo Koto Nagari Guguak Malalo Kec. Batipuh Selatan Kabupaten Tanah Datar. Penulis mengumpulkan data dengan memakai teknik pengumpulan data yang dilakukan dengan metode wawanacara, observasi dan dokumentasi.

\section{HASIL DAN PEMBAHASAN}

Diskursus Shalawat dan Tradisi Syaraful Anam

\section{Sekilas Tentang Living Hadis}

Living hadis di nusantara diawali dari berbagai fenomena Hadis dalam satu dekade belakangan ini. (Jajang A
Rohmana, 2015, 254) Fazlurrahman mempunyai pandangan bahwa hadis yaitu verbal tradition dan Sunnah yaitu pratical tradition atau silent tradition. Fazlur Rahman, 1994, 141) Ini dikembangkan dengan kajian bahwa sunnah yang dahulu baru kemudian muncul istilah hadis. Penyebaran hadis ini sendiri seiring dengang perkembangan penyembaran Islam. Maka Nabi Muhammad Sebagai pedoman dan teladan bagi Umat Islam diaplikasikan para sahabat, tabiin dan sesudahnya menjadikan perilaku nabi sebagai praktek keseharian. Sehingga ini disebut dengan Sunnah yang hidup (the living tradition)

Living Hadis artinya yaitu Hadis Nabi Muhammad yang dtuangkan oleh sahabat dan tabi'in menjadi amalan harian sehingga menjadi praktej jarian sampai saat ini. Pengamalan living hadis timbul dari beragam penafsiran individu terhadap hadis. (Suryadi, 2007, 93) Suryadi menerangkan bahwa living hadis yaitu Sunnah Nabi yang ditafsirkan secara bebas oleh para ulama, penguasa dan hakim sesuai dengan keadaan yang mereka hadapi. (Suryadi, 2007, 93) Adanya pergeseran pemikiran terhadap tradisi yang 
dianjurkan oleh Nabi Muhammad SAW, menjadikan hadis mempersempit cakupan pembahasan.

Living hadis itu sebuah tradisi masyarakat yang masih ada di tengah masyarakat didasarkan pada. Penyandaran itu bisa dikhususkan pada daerah khusus saja atau bisa lebih luad lagi dalam pelaksanaannya. (Muhammad Alfatih Suryadilaga, 2017. 111-113). Barbara D. Metcalf seperti yang dikutip Nikmatullah mengurai living hadis mempunyai makna ganda yang melingkupi pemahaman pada hadis dan internalisasi teks yang dilaksanakan dalam kehidupan nyata.

\section{Shalawat dan Urgensinya dalam Kajian Hadis}

Allah memberikan shalawat kepada Nabi SAW merupakan rahmat dari Allah, sementara shalawatnya malaikat mengharapkan kasih saying kepada Allah SWT. (Muhammad Alfatih Suryadilaga, 2017. 115). Ibnu Abbas mengurai bahwa maksud Allah SWT memberi shalawat ialah memberikan berkah. (Turmudi, 2008, 62) Hamka dalam tafsirnya mengungkapkan shalawatnya Allah kepada Nabi merupakan bentuk pujian yang diberikan kepada Nabi dan malaikat bershalawat kepadada Nabi ialah doanya. (Hamka, Tjmhn, 2015)

Pemaknaan Shalawat Allah kepada nabi berarti Allah curahkan rahmat kepada Nabinya Muhammad SAW. Shalawatnya malaikay pada Nabi berarti memohonkan ampunan pada Allah SWT serta mencurahkan perhatian pada Rasulullah. Sementara shalawatnya umat Islam kepada Nabi sebagai bentuk pengakuan kerasulan, serta Memohon pada Allah agar memberikan kemulian dan keutamaan padanya. Disamping itu umat muslim juga mengaharapkan syafaat Nabi Muhammad SAW. Ia juga bagian dari pernghormatan (tahiyyah).

Bershalawat pada Nabi Muhammad SAW merupakan perintah syari'at, sehingga ada waktu-waktu yang penting di dalam membaca shalawat, Ibnul Qayyim menyatakan ada 41 waktu (tempat) (Ibnu Qayyim, tth). Dimulai dengan shalawat ketika sholat di akhir tasyahud. Pada waktu itu para ulama sepakat tentang disyari'atkannya bershalawat untuk Nabi Muhammad SAW, namun mereka berselisih tentang hukum wajibnya. Di antara waktu lain yang beliau sebutkan 
adalah di akhir Qunut, kemudian saat khutbah, seperti khutbah Jum'at, hari raya dan istisqa', kemudian setelah menjawab muadzdzin, ketika berdo'a, ketika masuk dan keluar dari masjid, juga ketika menyebut nama beliau Shallallahu 'alaihi wa sallam.

Sejarah dan Pembacaan Syaraful Anam di Jorong Duo Koto Nagari Guguak Malalo Kec. Batipuh Selatan Kab. Tanah Datar

Keberagaman Masyarakat Jorong Duo Koto Nagari Guaguak Malalo

Bentuk keberagamaan masyarakat Jorong Duo Koto Nagari Guguak Malalo terlihat dengan kehidupan kemasyarakat yang religius. Islam dijadikan bagian dari ethnic identity, sehingga keberagamaan masyarakat Jorong Duo Koto Nagari Guguak Malalo memiliki ciri khas ke daerahan yang kental.

Jorong Duo Koto Nagari Guguak Malalo dari generasi ke generasi sampai saat sekarang ini berpahamahan tarekat Syatariah. Dimulai dari Uway Duo Koto Malalo.

\section{Sejarah Syaraful Anam}

Masuknya tradisi Syaraful Anam malalo, tidak lepas dari sejarah masuknya Islam ke Indonesia. Pendapat yang menguatkan tradisi ini ketika Islam dibawawa oleh ulama bermazhab Syafi'i. Ada pendapat yang menyebutkan Syeikh Maulana Malik Ibrahim dan wali songo yang dikenal menyebarkan Islam dengan cara toleran dan moderat. Seni Syaraful Anam dan berbagai shalawat lain juga yang menginspirasi wakisongo menciptakan lagu lir - ilir ataupun tombo hati.

Syaraful Anam yang merupakan bagian dari Barzanji ini banyak dilakukan di kalangan pesantren, terutama di bulan maulid. Kegiatan ini biasanya dilandaskan kepada para ulama maupun fuqoha. Ibnu Hajar AlAsqalani menyebutkan tradisi-tradi postif itu memiliki makna kebaikan (Solikhin, 2011: 77). Suyuthipun Memiliki sikap yang toleran terhadap produk budaya yang dihasilkan oleh tradisi mengagungkan kelahiran Rasulullah SAW. Sikap fuqaha ini pun diamini oleh fuqoha yang lain seperti al-Haytami dan Abu Shamah.

Peringatan Maulid Nabi meskipun tidak ada anjuran, tetapi bagi fuqoha semisal Haytami, Abu Shama, dll adalah suatu perbuatan baru namu terpuji (wa min ahsani ma ubtudi). Apalgi diiringi dengan berbagai kegiatan kebaikan lain seperti 
sadaqahm infaq, dan berbagai ibadah lainnya. Hal ini dinukil dari penggalan hadits berikut ini:

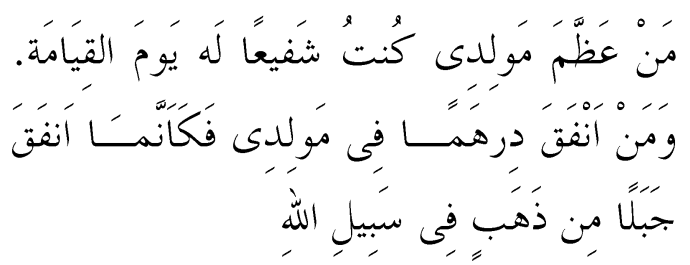

"Siapa yang menghormati hari lahirku, maka dia akan memperoleh syafaatku pada hari akhir kelak".

Dengan adanya sumber hadis inilah yang pada akhirnya kegiatan mauled marak dilakukan begitupula Syaraful Anam. Saat ini tradisi Syaraful Anam mulai dilakukan di berbagai kegiatan, tidak hanya maulid saja, tetapi ada di berbagai momen seperti saat lahiran anak, cukur rambut bayi, aqiqah, khitanan, nikah, dan berbagai momen lainnya.

Sejarah Syaraful Anam di Malalo menurut Angku Mudo (Angku mudo mendapatkan riwayat dari kakakanya Angku Katar. Bahwa Sejarah ini diceritakan oleh Uwai Angku Sungik kepada cucunya yaitu uwai angku talao. Dari uwai angku talao bersejarah kapada cucu beliau yaitu kakak Tk mudo angku katar namo beliau. Beliau pun termasuk pelaku syarafal anam) bermula dari Uwai Angku Sunguik, masanya sekitar 60 atau 70 tahun yang lalu. (Angku Mudo, Wawancara, 28 Oktober 2018) Ia berdomosili di duo dusun yaitu guguak dan duo koto. Landasannya wirid syarafal anam agar wirid ini dibaca dan didengar oleh masyarakat. Untuk itu diciptakanlah irama untuk syarafal anam.

Pada saat itu ada irama saluang dendang yang dikenal dengan lagu singkarak, untuk mempopulerkannya, Uway Angku Sunguik mengadopsi irama singkarak itu untuk irama yang dipakai dalam Syaraful Anam. Meskipun demikian iramanya di aransemen dan memiliki perbedaan juga dari lagu tersebut.

\section{Pembacaan Syaraful Anam di Bulan Maulid}

Waktu pembacaan kitab-kitab mauled, khususnya Syaraful Anam dilakukan pada hari dan momemn yang tertentu dan dipilih. Seperti wirid rutin lazim dilaksanakan pada hari senin karena masyarakat percaya mlam senin merupakan hari kelahiran nabi. Kemudian adapula yang memilih hari jum'at, karena sebagai hari agungnya umat Islam. Ada pula disebgian masyarakat yang merutinkan pembacaan sepanjang bulan Rabi' alAwal, bulan kelahiran rasulullah. 
Sakralnya pembacaan bias Pembacaan Syaraful Anam bagi terbangun oleh alunan pelantun dan masyarakat di Jorong Duo Koto Nagari prosa bacaan Syaraful Anam. Beda Guguak Malalo tidak hanyak pada daerah, beda pula cara pelafazan dan waktu maulid, tetapi juga dilaksanakan langgam bacaannya. Pujian dan pada waktu-waktu lainnya. Seperti sholawat pada Rasulullah dilakukan pada pesta pernikahan laki-laki. berulangkali. Pada momen tertentu, Pengantin laki-laki di Malalo tidak masyarakat adapula yang mengiringi dengan alunan musik. Sehingga menurut angku Mudo ini menimbulkan kekhusukan tersendiri da nada rasa kerinduan terhadap Rasulullah.

Seorang ulama Makkah Muhammad bin Alawi al-Maliki alHasani yang juga melestarikan tradisi bacaan maulid, memberikan penjelasan tentang fenomena pembacaan shalawat maulid ini. "Kegiatan atau tradisi ini memang tidak dilakukan di zaman nabi, ataupun umat terdahulu (salaf), akan tetapi bukan berarti hukumnya menjadi hara, tidak sunnah." Menurutnya ini adalah sikap gembira dan suka citanya umat Islam terhadap kelahiran rasul dan bershalawat atasnya. (Drs. K.H.A Idhoh Anas, 1999: 18-22)

Pembacaan Syaraful Anam di waktu Selain Maulid

Pembacaan Ketika Melepas Pengantin

di lepas dengan orgen atau musikmusik seperti saat ini, tetapi dilepas dengan membaca Syaraful Anam. (Mak Imam, Wawancara, 23 September 2018). Menutut Angku Mudo ini dilakukan agar pengantin pria yang akan menjadi kepala keluarga yang meneladani rasulullah SAW. (Angku Mudo, Wawancara, 28 Oktober 2018)

Biasanya pembacaan Syaraful Anam pada kegiatan melepas pengantin pria ini dilakukan malam hari. Sekita ba'da isya sampai pukul 12 malam. Tidak seluruh Syaraful Anam dibaca, tetapi hanya sebagian. Meskipun ada juga yang membaca sampai selesai, itu waktunya dari ba'da isya sampai subuh. (Ustaz Armen Agustian, Wawancara 18 Oktober 2018)

Tradisi ini menurut tokoh massyarakat sangat bagus. Karena anak tidak dilepas dengan nyanyian yang tidak bermamfaat, tetapi dengan 
pujian-pujian terhadap Nabi

Muhammad SAW.

\section{Pembacaan Ketika Ada yang Meninggal}

Ketika ada yang meninggal biasanya masyarakat di Jorong Duo Koto Nagari Guguak Malalo juga membacakan Syaraful Anam. Biasanya dilakukan dihari ke tujuh, seratus hari dan seterusnya.

Pembacaaan ini sendiri memiliki makna tersendiri bagi masyarakat malalo. Dalam hadis dijelaskan umat Nabi akan mendapatkan syafaat muhammad. Maka dari itu orang tua terdahulu berbedapat, bahwasanya orang yang meninggal tentunya juga dibacakan Syaraful Anam. (Hengki Africo, S.Pd.I, Wawancara, 28 Oktober 2018)

Diharapkan pembacaan ini bisa meringankan pula bagi si mayit dan orang yang ditinggalkan. Lama pembacaan Syaraful Anam untuk orang meninggal biasanya juga dilakukan di malam hari. Ada yang membaca setengah dan ada juga yang memaca sampai penuh. Tergantung permintaan ahli waris. (Cen Malano, Wawancara, 23 September 2018)

Pembacaan Sewaktu Akikah dan kegiatan lainnya
Ketika ada kegiatan seperti akikah, suntan menaiki rumah dan kegiatan kegiatan acara lainnya, bagi masyarakat di Jorong Duo Koto Nagari ini merupakan sudah menjadi tradisi.

Ini bertujuan agar nanti apaapun yang dilakasanakan, semua bermula dari pujian terhadap nabi Muhammad SAW. Sebagai umat, tentu mengharapkan syafaat dari rasul.

Tradisi Syaraful Anam, seharusnya menjadi spirit beragama bagi kaum muslim. Idealnya, Syaraful Anambukan hanya sebagai rutinitas saja. Esensinya yaitu spirit sejarah dan penyegaran ketokohan Nabi sebagai satu-satunya idola teladan yang seluruh ajarannya harus dibumikan. Figur idola menjadi miniatur dari idealisme, kristalisasi dari berbagai falsafah hidup yang diyakini. (Ustaz Armen Agustian, Wawancara 18 Oktober 2018)

\section{Pemahaman Masyarakat Jorong Duo Koto Nagari Guguak Malalo Tentang Tradisi Syaraful Anam \\ Respon Masyarakat terhadap tradisi Syaraful Anam}

Bagi masyarakat Jorong Duo Koto Nagari Guguak Malalo Syaraful Anam merupakan zikir yang dilakukan pada- 
pada waktu tertentu. Syaraful Anam atau kerap juga disebut zikir maulud yang telah dilakukan oleh masyarakat Malalo, merupaka pujian dan sanjungan terhadap nabi.

Mak Imam seorang pelaku maulid Syaraful Anam mengatakan bahwa Syaraful Anam memiliki dasar dari alQuran dan Hadis ${ }^{1}$. Menurutnya ini merupakan amalan yang perlu dilakukan. Bagi masyarakat Malalo ini merupakan tradisi yang sudah turun temurun diturunkan oleh orang tua terdahulu.

Dt. Bungsu mengunggkapkan bagi dirinya pribadi ada rasa di dalam hati ketika membaca Syaraful Anam. Memang mulanya dulu orang tua, yang menyuruh untuk membaca dan mempelajari, tapi sekarang sudah ada hikmah dari membaca Syaraful Anam itu. Memiliki ketenangan di hati.

Tradisi syair Syaraful Anam ini intinya yaitu memberikan pujian pada Nabi Muhammad SAW. Tradisi ini bermula dari Barzanji yang diperkenalkan oleh tiga penyair resmi Rasulullah SAW, yaitu Hasan Ibnu Tsabit, Abdullah Ibnu Rawahah, dan Ka'ab Ibnu Malik. Ini disebutkan

\footnotetext{
${ }^{1}$ Wawancara tanggal 3 Agustus 2018
}

dalam riwayat Ibrahim al Bajuri pada kita Hasyiyat al Bajuri 'ala Matn Qasidah al Burdah, tradisi pujian pada nabi Muhammad adalah tradisi yang perlu dibina dan dilestarikan oelh ummat Islam, agar mematuhi perintah Allah dan Rasul serta menjauhi larangannya.

\section{Pelaksanaan Syaraful Anam Bagi Masyarakat Duo Koto Malalo}

Syaraful Anam merupakan salah satu kitab yang bernafas Islam dengan tujuan berdakwah dengan seni. Bagi masyarakat Jorong Duo Koto Nagari Guguak Malalo pembacaan Syaraful Anam adalah tradisi dan diyakini oleh masyarakat akan mendapatkan pahala, karena dalam kitab Syaraful Anam mengandung perjalanan kehidupan, perilaku dan keteladanan Rasulullah. (Ustaz Armen Agustian, Wawancara 18 Oktober 2018)

Bagi masyarakat di Jorong Duo Koto Nagari Guguak Malalo pembacaan Syaraful Anam dikaitkan dengan berbagai acara, seperti acara maulid, Aqiqah, di wakti kematian dan melepas marapulai dan hari besar islam lainnya.

Kelestarian kepercayaan tradisi tersebut bagi umat Islam masyarakat 
Jorong Duo Koto Nagari Guguak

Malalo memiliki nilai-nilai kegaaman yang baik. Karena didialamnya spririt rasulullah, sejarah nabi semenjak lahir, hingga jadi rasul dilantunkan. Sehingga Menurut Amrizal, bahwa syair Kitab Syaraful Anam berisikan ajaran akhlak, ibadah, dan amaliah.

Ini disebut sebagai ibadah dan dakwah, disebabkan pembacaan Syaraful Anam merupakan perbuatan yang Ihsan. Sehingga setiap ibadah yang mengandung kebaikan dipercayai masyarakat akan mendapatkan pahala dari Allah. Kemudian pelaksanaan ini juga sebagai tradisi yang diamalkan dan hidup di tengah-tengah masyarakat dilandaskan kepada kemaslahatan.

Bisa dikatakan pelaksanaan Syaraful Anam adalah sebuah tradisi, yang dengan tradisi ini diyakini masyarakat sebagai sebuah pengamalan ajaran Rasul dan memuliakannya. Sehingga diyakini akan mendpatkan syafaat di hari kiamat kelak.

\section{Nilai-nilai Living Hadis dalam Tradisi Syaraful Anam}

Tradisi Syaraful Anam merupakan kegiatan yang memiliki nilai positif. Ada beberapa nilai living hadis yang terkandung dalam kegiatan ini, yakni sebagai berikut:

\section{Nilai Religius}

Pembacaan Syaraful Anam adalah bukti kecintaan masyarakat terhadap Rasulullah. Dengan dilandaskan dengan dalil-dalil keutamaan shalawat dan jaminan mendapatkan syafaat dari Rasulullah maka semngat religious muncul dari masyarakat.

Syair dalam kitab ini menjelaskan nilali-nilai, sejarah dan keteladanan Rasulullah. Sehingga bias meningkatkan kesadaran keimanan seseorang. (Mak Imam, Wawancara, 27 Oktober 2018. Selain itu, masyarakat dapat juga mengambil pelajaran dari kehidupan Nabi Muhammad SAW, sebagaimana yang ada di dalam kitab Syaraful Anam.

\section{Nilai Sosial}

Tradisi Syaraful Anam yang diadakan pada berbagai perayaan hari besar Maulid Nabi dan kegiatan lainnya (Cen Malano, Wawancara, 27 Oktober 2018) memberikan tempat bagi masyarakat untuk bersosialisasi keagamaan. Sehingga dengan kegiatan ini akan memperkuat silaturahim antar masyarakat. 
Nilai Budaya

Syair dan lantunan shalawat dalam Syaraful Anam merupakan sebuah jarya penghargaan kepada nabi Muhammad SA, karena dekat dengan unsur-unsur sastra yang bermutu tinggi. (Syahrial (Malin Mangkuto), Wawancara $27 \quad$ Oktober 2018) Sehingga muncul perpaduan pembacaan bahasa arab dan melayu dalam tradisi ini. Sehingga ini memperkaya khazanah budaya di Indonesia

\section{KESIMPULAN}

Tradisi Syaraful Anam merupakan upaya melestarikan tradisi yang telah dilakukan oleh ulama-ulama terdahulu dan sebagai upaya pengalama shalawat terhadap nabi serta bentuk kecintaan kepada Rasulullah yang diaplikasi dengan syair shalawatan.

Hal terpenting dari tradisi Syaraful Anam adalah pengalamalan dari hadishadis keutamaan shawalat yang tampak dalam majlis Syaraful Anam di Jorong Duo Koto Malalo. Dimana memiliki dampak dalam keseharian masyarakat.

Syaraful Anam merupakai produk budaya juga mengenalkan ajaran Islam yang disesuaikan dengan tradisi. Sehingga upaya budaya dan pendeketan dengan keislaman sudah terbentuk dengan tradisi pembacaan Syaraful Anam ini.

\section{REFERENSI}

Abdurrahman. A. 1996. Qaidah-Qaidah Fiqih (Jakarta: Bulan bintang)

Hamka, 2015. Tafsir Al-Azhar, Depok: Gema Insani

Rahman, Fazlur, 1994. Islam dan Islamic Methodology un History. Penerjemah Ahsin Muhammad. Bandung: Pustaka

Rohmana, Jajang A, "Pendekatan Antropologi Dalam Studi Living Hadis Di Indonesia: Sebuah Kajian Awal" Jurnal Holistic al-Hadis, Vol. 01, No. 02, (Juli-Desember) 2015, h. 254

Soetari, Endang, 2004, Otentitas Hadis Bandung: PT Remaja Rosdakarya

Suryadi, 2007. Dari Living Sunnah ke Living Hadis, dalam Syahiron Syamsuddin (ed), Mitodologi Penelitian Qur'an dan Hadis. Yogyakarta: Teras

Suryadilaga, Muhammad Alfatih, 2007. Model-Model Living Hadis, dalam Syahiron Syamsuddin (ed), Mitodologi Penelitian Qur'an dan Hadis. Yogyakarta: Teras

Tarobin, Muhammad, T.Th. Seni "Sarafal Anam" di Bengkulu: Makna, Fungsi dan Pelestarian. Jakarta: Balai Penelitian dan Pengembangan Agama

Thomas F. O'dea, 1996. Sosiologi Agama, terj. Tim Yasogama, Jaharta: Raja Grafindo Persada

Turmudi, 2008. Keagungan Shalawat 1001 Mukjizat dan Keajaiban 
Yang Terlupakan, Jakarta:

Pustaka Al-Mawardi

Wawancara dengan Mak Imam

Tanggal 23 September 2018

Wawancara dengan Angku Mudo

Tanggal 28 Oktober 2018

Wawancara Hengki Africo, S.Pd.I,

Tanggal 28 Oktober 2018

Wawancara Cen Malano, tanggal 23

September 2018 